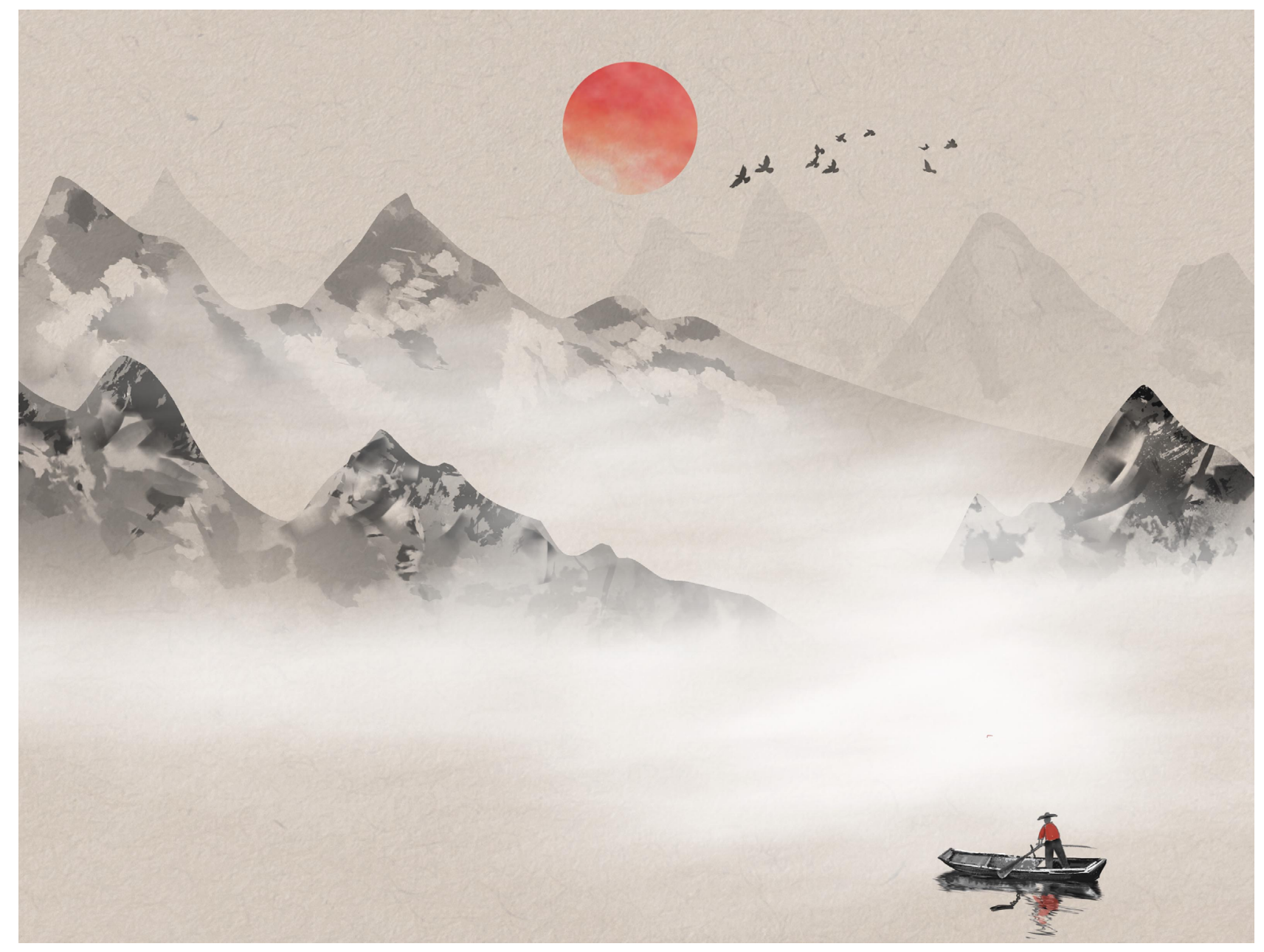

\title{
DESPEDIDAS E 0 PAPEL DA GV-EXECUTIVO NA DIFUSÃO DE CONHECIMENTO CIENTÍFICO EM ADMINISTRAÇÃO
}

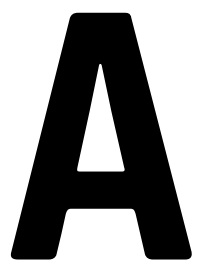

$G V$-executivo foi criada em 2002 (com o nome RAE-executivo) e completa exatos 19 anos neste mês de agosto. Ao longo dos anos, a revista já passou por diversas transformações, mas seu objetivo sempre foi propagar conhecimento inovador em gestão e provocar transformações de impacto nas práticas administrativas. Nesses últimos anos, em edições bimestrais, promoveu a disseminação de pesquisas aplicadas desenvolvidas nos 20 centros de pesquisa da Escola de Administração de Empresas de São Paulo da Fundação Getulio Vargas (FGV EAESP). 
Após cinco anos à frente da GV-executivo e da RAE-Publicações, encerro minhas atividades como editora-chefe da revista, honrada com a oportunidade e a autonomia que me foram dadas pelos diretores da FGV EAESP, professores Luiz Brito e Tales Andreassi, para contribuir com a difusão de conhecimento aplicado em gestão, trazer um debate crítico para líderes de organizações públicas e privadas e para alunos de pós-graduação em Administração, com foco no impacto social das pesquisas.

Ao longo dos anos, publicamos edições especiais sobre diferentes tópicos: transformação digital, gestão da saúde, desafios da área de supply-chain, gestão da mudança, gestão da inovação, finanças sociais, impacto social dos negócios, sustentabilidade, implicações da Covid-19 na gestão, entre outros. Destacamos também colunas sobre economia, gestão de pessoas, políticas públicas, responsabilidade social, além de entrevistas com lideranças empresariais.

A presente edição especial Perspectivas Brasil-China traz uma entrevista exclusiva com o Sr. Zhang Guanghua, CEO da filial brasileira do Bank of China, que trata do crescimento das relações entre Brasil e China. Os artigos que compõem a edição realçam a presença das empresas brasileiras na China. Xinjian Cui e Zixin Liu exploram o potencial para investimentos diretos das empresas brasileiras na China, em artigo com box de Chen Weihua e Chen Ziye sobre as oportunidades que surgem na Feira Exposição Internacional de Importação da China (CIIE). Maria Tereza Fleury aborda a presença das multinacionais brasileiras em território chinês, enquanto Taotao Chen versa sobre o caminho contrário das multinacionais chinesas em território brasileiro. Roberto Rodrigues discute o intercâmbio de negócios de produtos agropecuários entre Brasil e China como forma de estreitar a relação entre os dois países. Yen-Tsang Chen e Ely Laureano Paiva mostram a importância de respeitar a cultura chinesa na seleção de fornecedores nas cadeias produtivas.

Ressaltam-se, ainda, três artigos do especial sobre finanças: Hsia Hua Sheng e Natalia Diniz-Maganini apresentam o mercado chinês como opção para diversificação da carteira de investimentos no exterior; Amanda Leitner Thomazoni e Hsia Hua Shen expõem as possibilidades de se comprar e vender diretamente em renminbi; e Adrian Kemmer Cernev e Eduardo Henrique Diniz comparam os sistemas virtuais para pagamentos digitais de China e Brasil.
Completam esta edição o artigo sobre o papel da acreditação hospitalar na gestão da saúde, de Claudia A. S. Araujo e Ana Maria Malik; e o artigo sobre riscos emergentes na análise de investimentos ligados ao ASG (ambiental, social e governança), de Camila Yamahaki, Gustavo Velloso Breviglieri e Annelise Vendramini Felsberg. Nas colunas, temos: Cibele Franzese, que destaca o potencial da gestão em rede na administração pública; Sérgio Amad Costa, que debate sobre como a renda foi afetada na crise atual e os aprendizados no âmbito do trabalho durante a pandemia; Marina Gama e Jeferson Lana, que discorrem sobre a necessária cooperação entre empresas, organizações não governamentais (ONGs) e governos para a recuperação social no pós-pandemia; e Paulo Sandroni, que aborda as possíveis alternativas para o aumento da arrecadação no atual cenário econômico.

Faço minha despedida com a alegria do dever cumprido e com a certeza de que a $G V$-executivo continuará exercendo seu papel de disseminação de conhecimento científico em administração, com o novo editor-chefe, professor Thomaz Wood Jr., justamente o criador da RAE-executivo, em 2002. Recentemente, a FGV EAESP recebeu o reconhecimento internacional por seu impacto na sociedade, pelo BSIS Impact, do European Foundation for Management Development (EFMD). Apenas 56 escolas de 18 países já foram distinguidas com esse selo, e a FGV EAESP é a primeira da América Latina a obter esse reconhecimento, trabalho que contou com o apoio do professor Thomaz, cujas pesquisas estão voltadas à questão do impacto social das escolas de negócios. Certamente, o novo editor-chefe da $G V$-executivo trará inovações à propagação de conhecimento produzido nos centros de pesquisa da FGV EAESP, com ainda mais impacto e transformações para o desenvolvimento do país, missão da Fundação Getulio Vargas.

Aproveito para agradecer o apoio inestimável da equipe RAE-Publicações: Andrea Cerqueira, Denise Cândido, Eldi Soares, Ilda Fontes e, em especial, diretamente na GV-executivo, Aline Santos, jornalista, e Adriana Wilner, editora-adjunta, que me acompanharam nesses anos. Gratidão imensa por todo o apoio.

Muito sucesso para o novo editor-chefe, Thomaz Wood Jr.

Boa leitura

Maria José Tonelli - Editora chefe 